\title{
Metastatic Lung Adenocarcinoma
}

National Cancer Institute

\section{Source}

National Cancer Institute. Metastatic Lung Adenocarcinoma. NCI Thesaurus. Code C155908.

Lung adenocarcinoma that has spread from its original site of growth to another anatomic site. 